\title{
INVESTIGATING THE FEASIBILITY OF DIGITALLY CREATED INDUSTRIAL DESIGN SKETCHBOOKS
}

\author{
Bahar ŞENER*
}

Received: 25.06.2013; Final Text: 30.04.2014

Keywords: Sketchbooks; industrial design; design documentation; education; sketching.
* Department of Industrial Design, Faculty of Architecture, METU, Ankara, TURKEY.

\section{INTRODUCTION}

While externalising their thoughts and giving design ideas a physical form, industrial designers make use of various kinds of media, such as drawing on paper, constructing in foam or card, generating computerbased 2D and 3D representations, and so on. The creation of such 'models' or 'representations' of developmental design ideas fulfils two fundamental roles: to aid communication (mostly to other people) and to aid designing (mostly for the individual designer) (Wormald, 1997). To document their design processes, it is usual for designers to compile a physical (i.e. paper-based) sketchbook of design activity. A comprehensive sketchbook is recognised as a portfolio collating all the materials that a designer generates, collects, is inspired by, consults, researches, observes, reads etc. during the progression of a design project from the very beginning to the delivery of final outcomes. Such use of paper-based notebooks and sketchbooks is well documented across creative practices (Tabard et al., 2008; Brereton, 2009).

Although the term 'sketchbook' implies the presence of graphical content, in the sense that sketches are conventionally understood as drawings made on paper, the term is actually more encompassing. Pedgley (2011) presented an overview of sketching as a more general activity for industrial designers, and emphasized that sketching is not tied to any particular modelling medium or to either 2D or 3D representations. Rather, sketching exists as a generative and communicative process, characterized by the creation and 'working up' of embryonic and emerging design ideas within a fluid solution space, independent of modelling media. O'Neill (2011) and Unwin (2009) discuss how sketchbooks are not simply an externalisation of memory or a repository of ideas and information, but crucially provide a 'playful' open space that prompts reflection and affords the reconfiguration of ideas. The consecutive pages of a sketchbook are a very powerful resource for narrating the progression of design stages: they provide a 
tangible trail of design thinking, design management, and communication of ideas (O'Neill, 2011; Baskinger, 2008; Warburton, 2001; Kavakli et al., 1998). Maintaining a 'good' sketchbook is therefore regarded as an important professional activity (Winjen and van den Hoven, 2011).

In an educational context, sketchbooks are frequently an assessed component of a design project submission. They allow design development to be communicated and tracked, feedback to be given, and for the overall quality of the student's design processes to be assessed. When we look at the educational experience of students attending design project studios, students benefit most from instructors' advice when they are able to regularly present their sketchbooks as a rich stimulus for a design dialogue. In this way, sketchbooks become a 'hub' for the student's design activity. When students encounter a 'sticking point' in their projects, a comprehensive sketchbook permits instructors to revisit previous work and suggest alternative or new routes for design exploration.

The modern design studio is, however, a digital workplace. Digital media and design tools are ubiquitous and digital communication is the default mode of exchanging ideas amongst geographically distributed project stakeholders. Across the timeframe of an industrial design project, we generally see designers' activities become increasingly digital, eventually arriving at the generation of photorealistic computer-generated visualizations of finalized design proposals. So within this digital world of design, the suitability of a paper-based sketchbook for effectively generating, capturing, compiling and communicating design development activity is questionable. Furthermore, important advantages of working in a digital medium - such as 'undo', 'redo', distribution, networking, and storage across multiple devices (O'Neill, 2011) cannot be ignored. The focus of the work presented in this paper is on the feasibility of transitioning from paper-based to digital-based, as the de facto format for industrial design students' sketchbooks.

\section{PROBLEM DEFINITION AND RESEARCH QUESTIONS}

The migration to digital design processes and digital media presents the problem that paper-based sketchbooks become incompatible for maintaining a sufficient history of project progress. In essence, paperbased sketchbooks cannot be used to effectively document digital design processes. The iterative steps made during digital design development, which may involve the use of CAD (computer aided design) or the generation and manipulation of digital media (e.g. video, image, web content), cannot be conveniently compiled or navigated. We observe that students attempt to circumnavigate the problem by printing out digital files, so that they may be added to their paper sketchbooks and annotated. CAD screenshots are sporadically printed, to try to document the digital form creation process, but this rapidly becomes an arduous and incomplete task. For some students, digital content is skipped entirely and does not appear in sketchbooks. The end result of these problems is that the rich dialogue that is expected during design critiques becomes suppressed, whilst the mechanism for assessing a student's design process breaks down. Thus, the overall value of students' physical sketchbooks - both to students themselves, and to instructors - becomes diminished when digital design processes cannot be properly captured. 
Problems with paper-based sketchbooks are not confined to content generation and presentation. We observe that students are also unsatisfied with the lack of portability of paper-based sketchbooks (which, for the author's design studio, are requested in A3 format), whilst the inherent consumption and wastage of paper is a concern for everyone involved. It may therefore be advantageous to ask students to prepare and submit their sketchbooks entirely digitally, with the intention that paper/digital incompatibilities can be removed and concerns over portability and paper consumption can be addressed. With this proposition in mind, three research questions were investigated through the work reported in this article.

Q1. Willingness - How willing are industrial design instructors and students to use a digital sketchbook for studio projects?

Q2. Expectations - What do industrial design instructors and students expect to accomplish through a digital sketchbook?

Q3. Implementation - What kind of hardware and software are needed for a practical realization of a digital sketchbook in an educational context? How is the student experience of generating such a sketchbook?

After completing a review of literature on previous digital design sketchbook studies (reported in the following section), we observed that no practical assessment had yet been made regarding the opportunities and barriers of transitioning from physical to digital sketchbooks in an industrial design education context. In response, in January 2013 a feasibility study involving a modest number of students and instructors of METU Department of Industrial Design was undertaken, with the intention to scope out the main underlying issues and to reach preliminary conclusions on what a 'good' digital sketchbook platform for industrial design students might be like. Such a feasibility study was considered a necessary prerequisite before embarking on a larger-scale project to define, design and implement a digital sketchbook suitable for use by a full studio class.

\section{DIGITALIZATION OF DESIGN DEVELOPMENT: A COMMON GOAL}

The subject of digitalizing design development processes has run a thread throughout research studies from the early 2000s onwards. Three different levels of digitalization are found in literature, representing ever-increasing reliance on digital media and tools.

a) Digital sketching (i.e., performing digital equivalents of 'pen-andpaper' visualization of design ideas).

b) Digital sketchbook (i.e. use of a digital platform to document design activities that may be performed digitally or non-digitally).

c) Digital workflow (i.e. performing and documenting an entirely digital design process, absent of non-digital activities).

Most prior art has focused on (a), whereas the concern for this present paper is (b). However, it should be noted that since digital design processes are not transferred well to paper-based sketchbooks, so we may assume paper-based design processes are not transferred well to a digital-based sketchbook. Researchers engaged in (b) therefore tend to simultaneously 
embrace (a), so that the effort to scan paper-based media is minimized. To examine the progression of research studies in the area of digitalized design development, it is useful to make a chronological review, since doing so reveals the essential influence of increasingly advanced technologies.

In an early visionary study, Hoeben and Stappers (2001) generated scenario-based videos to examine ways in which technology envisaged for now could be used to generate a digital sketchbook. They emphasized a need for portability and intelligent design support. Jonson (2002) presented a detailed analysis of the nature of 'sketches' and 'sketching', as a precaution against too much enthusiasm towards adopting digital sketching without first properly understanding its non-digital counterpart. Similarly, Reffat (2002) explored the teaching and learning implications of a paperless architectural design process, absent of the traditional sketchbook. A recurring theme in literature, and exemplified by Stappers and Sanders (2005), is the need for tablet-based sketching software to better replicate established interaction qualities and methods of pen-and-paper sketching. Or, as Lee et al. (2006) report through their 'iDeas project', rather than mimicking existing methods, it can be more desirable to integrate physical and digital technologies under the broad principle of 'augmented paper systems', which essentially comprise ways to layer additional digital content onto a 'traditional' paper-based idea log or sketchbook.

From the late 2000s, we see a larger number of studies based on development and evaluation of commercial and Research-andDevelopment tablet-based sketching systems. Chin and Tan (2007) assessed the use of tablet PCs running SketchBook Pro software, as a learning and assessment tool for students and teachers, as well as a means to compile a digital design sketchbook to document design activity and, in particular, student-tutor graphical dialogues. Oehlberga et al. (2009) made a crosscomparison of tangible, digital and hybrid engineering design sketchbooks (or 'journals' in their terminology) across a four-year period, regarding their differential uptake, presentation and content. Weibel et al. (2011) proposed solutions for remote collaborative sketching on "interactive paper", involving a shared digital workspace where each participant sketches with a digital pen.

In 2010, the Apple iPad was launched, with specifications that would lend itself well to the creation of a digital sketchbook. As well as 'SketchBook Pro', other applications such as 'Ideate' have been developed, aiming to utilize iPad functionalities for sketching, clipboarding and sharing (Sanchez, 2010). At the same time, more tangible approaches based on new technologies emerged. For example, the 'connected sketchbook' concept by Wijnen and Van Den Hoven (2011) offered an editable link between (i) an archive of digital information presented as virtual pages, and (ii) the pages of a physical sketchbook, accessed through an RFID tag system. Research studies fundamentally questioning the feasibility and desirability of fully or near-fully digital design processes also arose in parallel. For example, a preliminary study on the replication of physical sketchbook content in digital media, and consideration of impacts on the support of designers' creativity ( $\left.\mathrm{O}^{\prime} \mathrm{Neill}, 2011\right)$; and, the mixed reaction of students and employers towards the idea of an entirely digital workflow (Al-Doy and Evans, 2011).

The most recent works continue to use tablet-based computing as their foundation. Li et al. (2012) showcase 'SketchComm' as a tool for supporting 
distributed, asynchronous generation and communication of early-stage multimedia design sketches, whilst uniquely also capturing essential information typical of face-to-face communication. Wu et al. (2012) look at how digital sketching with a Wacom system can influence design thinking and visualization strategies, compared with pen-and-paper sketching. With specific reference to iPad-based systems, Wang and Karlström (2012) established that 'mobility' and 'multi-modality' are the most defining positive features for undergraduate interaction design students asked to maintain a digital sketchbook.

One particularly intriguing research project has sought to bridge the gap between physical and digital sketching by the use of a digitising pen that also utilizes gestures to 'flick' a hand prepared sketch onto a display (Pao et al., 2012). The integration of such tools into students' design processes during studio education, and the need for educators to respond to their positive and negative effects, can be expected to be of increasing importance. Furthermore, recent concern about the practicalities of creating an 'e-sketchbook' in art and design educational contexts, and the potential pitfalls of a system reliant on student self-management of content and files (NSEAD, 2013), confirms that the pursuit of a successful digital sketchbook system is presently a shared and important goal amongst the design research community.

\section{FEASIBILITY STUDY STRUCTURE}

The feasibility study was structured into four sequential stages, each building a better understanding of the issues involved in transitioning from paper-based to digital-based industrial design sketchbooks.

- In stage 1, an analysis of approximately 60 paper-based student sketchbooks was made, to expose in a systematic and orderly way the various modes of representation used in industrial design development processes. Such content analysis was not obtainable through the literature reviews supporting this article. The results give an insight into what content may be expected of a digital sketchbook.

- In stage 2, semi-structured interviews were conducted with five instructors and five students regarding perceived strengths and weaknesses of paper-based and digital sketchbooks. The results serve to answer the research questions regarding willingness and expectations.

- In stage 3, a technology review for digital industrial design sketchbooks is reported, leading to rationale for selecting the hardware and software suitable for trialling a student-based digital sketchbook platform.

- In stage 4, five graduate industrial design students created digital sketchbooks during a short concept design project, followed by the completion of a post-project questionnaire. The results serve to answer the research question regarding practical implementation.

Each stage now reported discretely, regarding its methodology and outcomes. Discussion of the key lessons learned and the main conclusions are presented at the close of the paper. 


\section{STAGE 1 - REVIEW OF PHYSICAL SKETCHBOOKS}

At this stage, the aim was to expose and understand what the typical content of a sketchbook is, with regard to the modes of representation used (e.g. text, diagrams, freehand sketches, etc.). A review of approximately 60 final year (Year 4) undergraduate industrial design students' physical sketchbooks was made with three colleagues (i.e. three independent analyses, followed by a consensus discussion), to reach a classification on the kinds of content that students generated. Two approaches to classification were considered: according to i) modes of representation; or ii) design purposes. 'Modes of representation' was chosen since it most directly related to ability (or not) to reproduce the variety of graphical elements that might be reasonably expected in a digital sketchbook. The alternative - according to 'design purpose' - was not preferred, from the standpoint that the purpose of using a certain mode of representation could vary and depend on each individual designer's creativity, ability, preferences, personal style, demands of a specific project etc.

Table 1 provides modes of representation within sketchbooks (column 1); accompanied by example usages/purposes (column 2), and a representative visual (column 3). Unsurprisingly, some sketchbook content reflected what was specifically asked of students as part of their project requirements, whilst the remaining comprised students' individual approaches to proceeding and documenting their design process. Nevertheless it illustrates the rich results that were obtained regarding the variety and similarity of content across the sketchbooks. Having analysed approximately half of the 60 sketchbooks, a saturation point was reached at which point no new categories for 'modes of representation' were defined. It was noted that many individual pages of the analysed sketchbooks featured more than one mode of representation.

Aside from the findings described in Table 1, it is also noted that the 60 studied designers approached the presentation and compilation of their sketchbooks in notably different ways, regarding navigation, layout and page size.

Navigation: Some students added separator pages, an index page, page numbering or tabs (indicating chronological project phases) to facilitate navigation through the sketchbook.

Layout: Some students preferred free-flowing idea presentation on a page, whereas others preferred a more organised way of presenting, e.g. area divisions on the same page or creating page layout grids.

Page size: Some students worked on different page sizes from A1 down to pocket notebooks (defying the requested A3 format), in which case they either folded their pages or enlarged their drawings by photocopying to retrospectively fit the $\mathrm{A} 3$ format.

\section{STAGE 2 - OPINIONS OF STUDENTS AND DESIGN STUDIO INSTRUCTORS}

This stage involved semi-structured interviews with five instructors and five students regarding their expectations, opinions and perceived strengths and weaknesses of adopting a digital sketchbook. It helped to determine the kinds of management issues that might arise in the transition to a digital format. The findings, reported in Table 2, revealed detailed reasons for keeping a physical sketchbook; expectations for the 


\begin{tabular}{|c|c|c|c|}
\hline $\begin{array}{c}\text { Mode of Representation } \\
\text { and Explanation }\end{array}$ & Example Usages/Purposes & & Representative Visual \\
\hline $\begin{array}{l}\text { TEXT (alpha-numerical) } \\
\text { handwritten, typed, variation in } \\
\text { font sizes } \\
\text { words; phrases; sentences; } \\
\text { paragraphs }\end{array}$ & $\begin{array}{l}\text { e.g. } \\
\text { - annotations for photos } \\
\text { - problem definition } \\
\text { statements } \\
\text { - title for work } \\
\text { - product material list }\end{array}$ & $\begin{array}{l}3 \\
\frac{3}{2} \\
\frac{3}{2} \\
\frac{1}{2} \\
0\end{array}$ &  \\
\hline $\begin{array}{l}\text { DIAGRAMS, CHARTS and } \\
\text { GRAPHICAL ELEMENTS } \\
\text { highlighting bubbles / boxes / } \\
\text { shapes / lines / colours; arrows / } \\
\text { relational information; graphs; } \\
\text { tables; flowcharts }\end{array}$ & $\begin{array}{l}\text { e.g. } \\
\text { - elements of a mindmap } \\
\text { infographics }\end{array}$ & 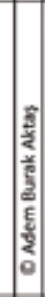 & 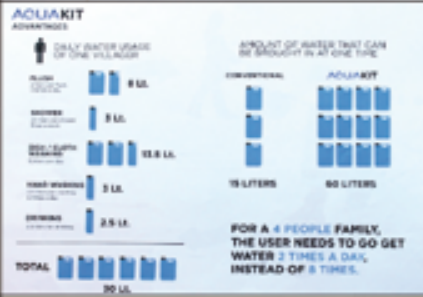 \\
\hline $\begin{array}{l}\text { SKETCHES } \\
\text { freehand drawings; computer- } \\
\text { touched-up drawings }\end{array}$ & $\begin{array}{l}\text { e.g. } \\
\text { - product visualisation } \\
\text { - idea generation } \\
\text { - storytelling }\end{array}$ & 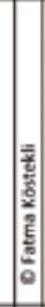 & \\
\hline $\begin{array}{l}\text { IMAGES } \\
\text { photographs; Internet downloads; } \\
\text { photocopies and scanned images }\end{array}$ & $\begin{array}{l}\text { e.g. } \\
\text { - user profiling } \\
\text { - model-making process } \\
\text { - moodboard }\end{array}$ & 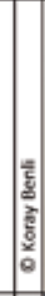 & \\
\hline $\begin{array}{l}\text { PRODUCT GRAPHICS and } \\
\text { SYMBOLS } \\
\text { freehand or computer generated }\end{array}$ & $\begin{array}{l}\text { e.g. } \\
\text { - interface elements } \\
\text { - instructional symbols } \\
\text { - logotypes } \\
\text { - iconography }\end{array}$ & 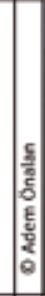 & \\
\hline $\begin{array}{l}\text { CAD } \\
\text { renderings; technical drawings; } \\
\text { screenshots }\end{array}$ & $\begin{array}{l}\text { e.g. } \\
\text { - photorealistic visualisation } \\
\text { exploded orthographic, } \\
\text { - screenshots of 3D } \\
\text { modelling in progress }\end{array}$ & 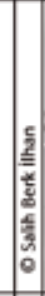 & \\
\hline $\begin{array}{l}\text { PHYSICAL ADD-ONS } \\
\text { students' use of additional } \\
\text { material to literally create an extra } \\
\text { layer of information onto a } \\
\text { sketchbook page }\end{array}$ & $\begin{array}{l}\text { e.g. } \\
\text { - sticky notes } \\
\text { - diary booklets } \\
\text { - material samples }\end{array}$ & 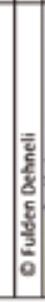 & $=\frac{7}{0}=2=5$ \\
\hline
\end{tabular}


Reasons for Keeping a Paper-Based Sketchbook

- Instructors: documentation of design process; single location for students' developmental work; tracing project progression; medium for generating and experimenting with ideas; medium to exercise drawing skills; medium for communication between tutors and students; paper is relatively cheap and easy to maintain and store.

- Students: it is a project submission requirement.

Perceived Inadequacies of Paper-Based Sketchbooks

- Instructors: insufficient and inefficient presentation of developmental work; poor quality of sketching; reluctance and lack of confidence in quick hand rendering; lack of fluency in idea presentation; inability to capture design intent/commentary during CAD modelling periods; not a medium that students are satisfied with; difficulties to document field research, observations, mock-ups etc.; gaps occur in project documentation.

- Students: not a very practical medium; cannot easily or comprehensively capture work occurring 'outside of paper' (e.g. Internet searches, user studies etc.); poor hand visualization skills leads students to scan sketches and touch-up on computer.

Perceived Advantages of Creating a Digital Sketchbook

- Instructors: portable; space-saving; accessible from anywhere; more thorough documentation; better sharing possibilities through data transfer and social networks (e.g. Facebook, Pinterest); easier tracking of progress; generated independent of time and place; easier to create convincing visualizations; easier to prepare design variations (e.g. repeating saved sketches, application of different colour and material options); interactive presentations using various media; typed text is more legible than handwriting; may be reorganized not just chronologically; no need to carry bulky papers; overcomes printing related problems.

- Students: ability to experiment with product scaling; risk-free sketching with undo / redo; better organization and archiving; natural step towards preparing digital design portfolio; ability to document animations, videos, and photographs.

\section{Perceived Difficulties in Creating a Digital Sketchbook}

- Instructors: steep learning curve for proficiency in new technology; new skills in digital record-taking and archiving; should be integrated into relevant courses (NB not just one course); cost of hardware and software and implications for universal access; need for periodic technology upgrades; management of files; non-permanent medium because of file format changes; possibility of file corruption and loss of access to files (NB frequent and reliable backup needed); incompatible with group exercises using large surface area sketching; restricted use of digital devices in some locations (e.g. museums); technological constraints may limit creativity; lack of 'hands-on' experience and 'personal touch'; not able to solve problem of documenting stages of CAD modelling.

- Students: lack of prior experience in such a medium; inefficient use of time; not feasible to replicate multiple sketch books (i.e. multiple screens, simultaneous use); inability to 'spread out' many sketches on a large surface; may not be as portable as a small paper sketchbook; not always desirable to carry a digital device.

content of sketchbooks; and whether students were able to sufficiently and efficiently present their project processes through their sketchbooks. In Table 2, comments from students are listed only if they are additional to the comments mentioned by instructors. 


\section{STAGE 3 - DETERMINING AND USING A SUITABLE DIGITAL SKETCHBOOK}

Stage- 3 comprised a criteria-based evaluation of potential hardware and software that could be combined to form a digital sketchbook platform. In light of the technology review completed under the following section, the aim was to define a system that primarily offered a 'computer equivalent of pen-and-paper sketching', but with capability to support other modes of representation. We cannot propose that the final choice represents the 'best' performing or suited system (since multiple systems were not tested), however we do claim that the system is well specified based on the criteria that we set.

\section{Digital Equivalents of Pen-on-Paper Sketching}

Of the modelling media used by designers, sketching (on paper) is inherently convenient as a way of depicting ideas during design ideation and development (Weaver, 2009; Shillito et al., 2003; Hummels, 2000; Ottosson, 1998; Temple, 1994). Paper is easy to annotate, cheap, lightweight, foldable, mobile and requires no power source (Wijnen and van den Hoven, 2011). Not surprisingly, the vitality and personality of sketched freehand drawings is a theme that permeates throughout research literature on modelling and design, and is central to designers' developmental activities captured in their design sketchbooks (Weibel et al., 2011). It is therefore important to determine whether there are credible digital alternatives for pen-and-paper sketching, since these would undoubtedly form a foundation for a successful digital sketchbook.

The literature review revealed many digital systems supporting professional sketching activity, although none go so far as to reproduce all of the interactive qualities experienced when working with pen and paper. The skills of drawing and freehand visualization are undoubtedly still vital in design education, but as design studio instructors we realize that new generations of students are increasingly 'digital-aware' and that 'working with pixels' is, for them, as familiar as 'working with pen marks'.

Sketching, traditionally performed with pen-and-paper and enriched with a designer's personal skills and self-expression, is still poorly implemented in today's 3D CAD systems. Even the basic CAD tools - a laptop, keyboard and mouse - have no related affordances to pen and paper. Thus a common way to 'digitalize' pen-and-paper sketching is to use creative 2D visualization software such as Adobe Photoshop and Illustrator, often running on a tablet PC or graphics tablet with a stylus-based input. Penbased human-computer interaction is said to be natural, easy, creative and efficient for expressing ideas (Zheng et al., 2007). Wacom ${ }^{\circledR \prime}$ s Intuos ${ }^{\circledR}$ and $\mathrm{BAMBOO}^{\mathrm{TM}}$ family of professional multi-touch and wireless pen tablets, styli and accompanying software applications represent a further step up in functionality, providing solutions specifically targeted at designers, illustrators and artists. Tablet systems do not require numeric data entry and have consequently emerged as the closest digital equivalent of using pen-and-paper.

The use of high resolution full-colour tablet PCs - and touchscreen mobile devices more generally - has expanded dramatically in the last two years. The market is full with highly attractive, sleek and powerful devices having typically very thin and lightweight bodies, excellent portability and mobility, Wi-Fi and $3 \mathrm{G}$ network connectivity. Furthermore, a wide variety of software applications are available for these tablets, spanning 
communication, imaging, and multimedia manipulation, as well as applications and accessories specifically supporting design work. Examples include Apple iPad, Samsung Galaxy Tab 10.1 Tablet, Asus Google Nexus Tablet, and Wacom Cintiq Interactive Pen Displays. Designers can interact with the screen surface of these devices as if they are drawing on paper, since pen marks appear directly where they touch the screen. With the help of software, line thickness, colour, transparency, nib type, patterns, 'paper' colour and quality etc. can be easily set and switched.

As pointed out by Ginsburg (2011), touchscreen tablets hold much promise as design tools, but they present several limitations. First, the screen size does not approach the typical $9 \times 12$ " dimensions of a paper sketchpad. Secondly, capacitive screens cannot sense pressure, which makes it impossible to incorporate common sketching techniques such as pressurebased shading. And thirdly, even the most recent tablets cannot produce ballpoint precision, regardless of the application or stylus being used. This is because of a technical limitation in the ability of low-resolution sensor panels to detect the input from a stylus; hence most styli have relatively large nib tips.

Many software applications exist for tablet users to make drawings. These applications range from the very simple (for doodling, annotations, colour sketches and touch-up, e.g., Paper I FiftyThree, Adobe ${ }^{\circledast}$ Ideas, $\mathrm{Si}^{\mathrm{TM}}$ ProCreate $^{\circledR}$ ) to those that gradually offer more professionally relevant sketching, full-colour drawing, rendering, and even 3D modelling. For example, Autodesk SketchBook Pro ${ }^{\mathrm{TM}}$ allows designers to draw, colour and write on a tablet screen using multiple layers. CATIA V6 Industrial Design software recently introduced 'Natural Sketch' as a better recreation of pen-and-paper sketching in 3D: the software converts 2D sketches made on a tablet into 3D sketch curves to create an editable 3D model. As well as software, the weight, grip, length, texture, tip material and tip size of hardware styli are an important factor in 'digital sketching' and resemble similar characteristics that determine each designer's personal preferences for a certain brand and type of pencil or pen.

Building on this, the following sections present the specific criteria set for choosing the digital sketchbook hardware and software. In both cases, relatively low costs were an important factor, since the proposed system would in principle need to be affordable to students.

\section{Rationale for Choosing Hardware}

The principal selection criteria for the hardware were: portability; low weight; ability to directly draw onto a screen with a stylus; built-in camera (for still and video photography); 4G mobile telephone network connectivity (for cloud computing outside of Wi-Fi zones); compatibility with suitable software (see 'software', below); total expenditure within the financial limits of the project budget; availability in local stores. The final choice was an Apple ${ }^{\circledR}$ iPad (tablet PC, 64GB, Wi Fi + 3G, Retina Display) and Just $\mid$ Mobile $^{\circledR}$ AluPen $^{\mathrm{TM}}$ (stylus for iPad), shown in Figure 1. The AluPen was chosen in preference to alternatives (e.g. Pogo, Stylus Socks, Bamboo), because product reviews had concluded that it performed equally well for sketching and writing, unlike the other styli which tended to be suited for one or other activity but not both. In choosing the iPad, we also sought a digital device that would serve as an everyday portable/ mobile computing device capable of daily applications such as scheduling, emailing, and web browsing. This would remove the need to impose a 
specialist 'sketching only' device on participants. The Apple iOS platform also offered a great variety of free or low-cost applications to download and install instantly. At the time of purchase, closest alternatives (e.g. Samsung devices) had limited availability in the local market.

\section{Rationale for Choosing Software}

The principal selection criteria for the software were: supportive of designers' sketching; downloadable; inexpensive; compatible with Dropbox (an Internet-based file storage and sharing service in widespread use amongst our students and colleagues). The final choice was a combination of 'Autodesk SketchBook Pro ${ }^{\circledR}$ ' and 'Paper by Fiftythree'. 'SketchBook Pro' is a highly-regarded professional-grade paint and drawing application targeted specifically at designers, artists and illustrators (Autodesk, 2014). Its developers, Autodesk, are one of the leading suppliers of professional CAD software (e.g. AutoCAD, Alias). Accordingly, the software is highly specified regarding the variety and quality of tools, working in layers, multi-touch support, annotations, customizable swatches, and compatibility with common file types. Taken as a package, SketchBook Pro was considered more favourable than alternative 'professional' iPad sketching applications including Layers Pro, Adobe Ideas, ArtStudio, Brushes, Zen Brush and Bamboo Paper. Nonetheless, it was considered important to also offer a much simpler software alternative, should participants wish to use it, without the features and functions of SketchBook Pro. 'Paper by Fiftythree' is an award-winning application (iPad Developer Showcase 2012) which was selected because it strips back the sketching experience to only the 'bare essentials', aided by gestural 'thumbing through' of pages. The interaction that it offers is closer to the experience (and limitations) of pen-and-paper sketching. A research participant making use of the portability of the chosen digital system can be seen in Figure 1.

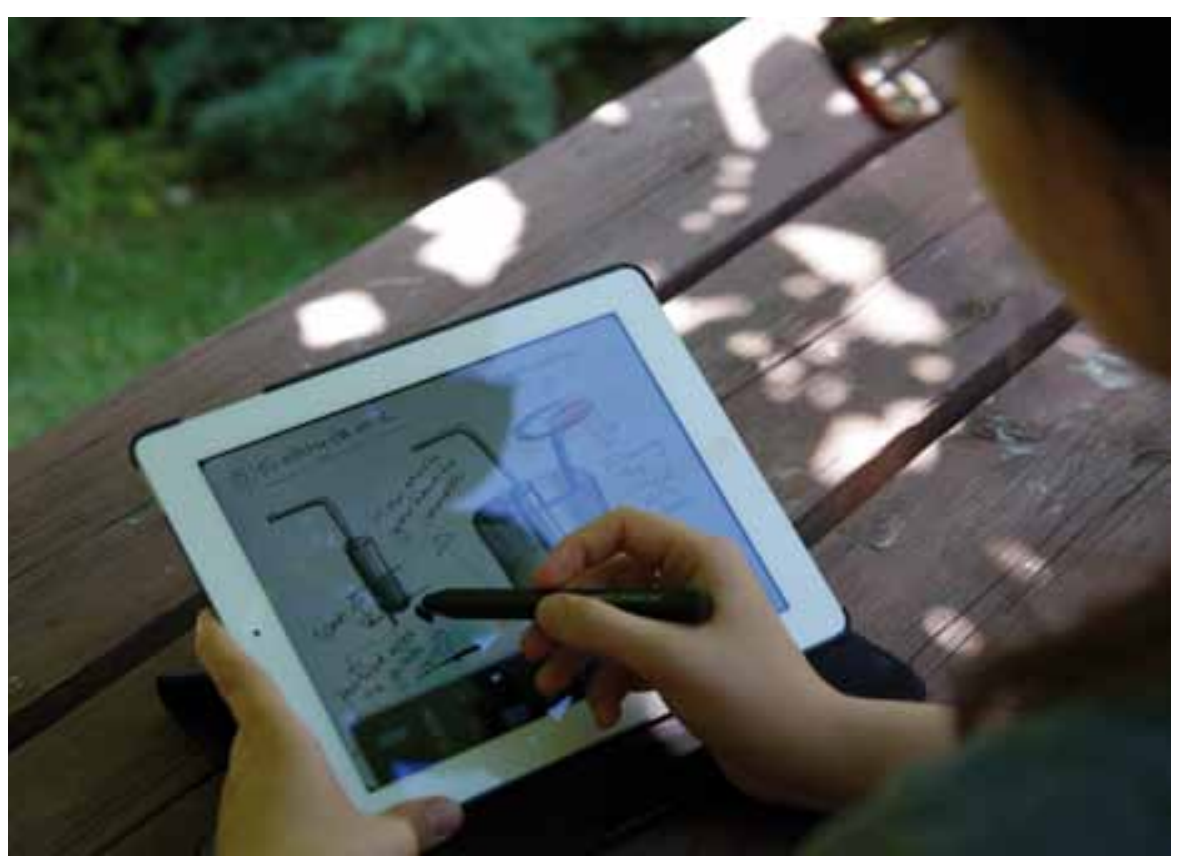




\section{STAGE 4 - CONCEPT DESIGN PROJECT}

This stage involved five volunteer postgraduate industrial design students working on a six-week concept design project on the combined theme of 'design for interaction' and 'coffee-making experiences'. The project served as a pilot investigation for how to create and manage a digital sketchbook. Compared with undergraduate studio projects, students had considerably less tutor contact time and less allocated free time to reach a finalized design proposal. Therefore, the educational expectations were different than for undergraduate studio projects, though the project was still managed through in-class exercises, presentations and one-to-one design critiques. The project progressed through three phases of work: (i) problem

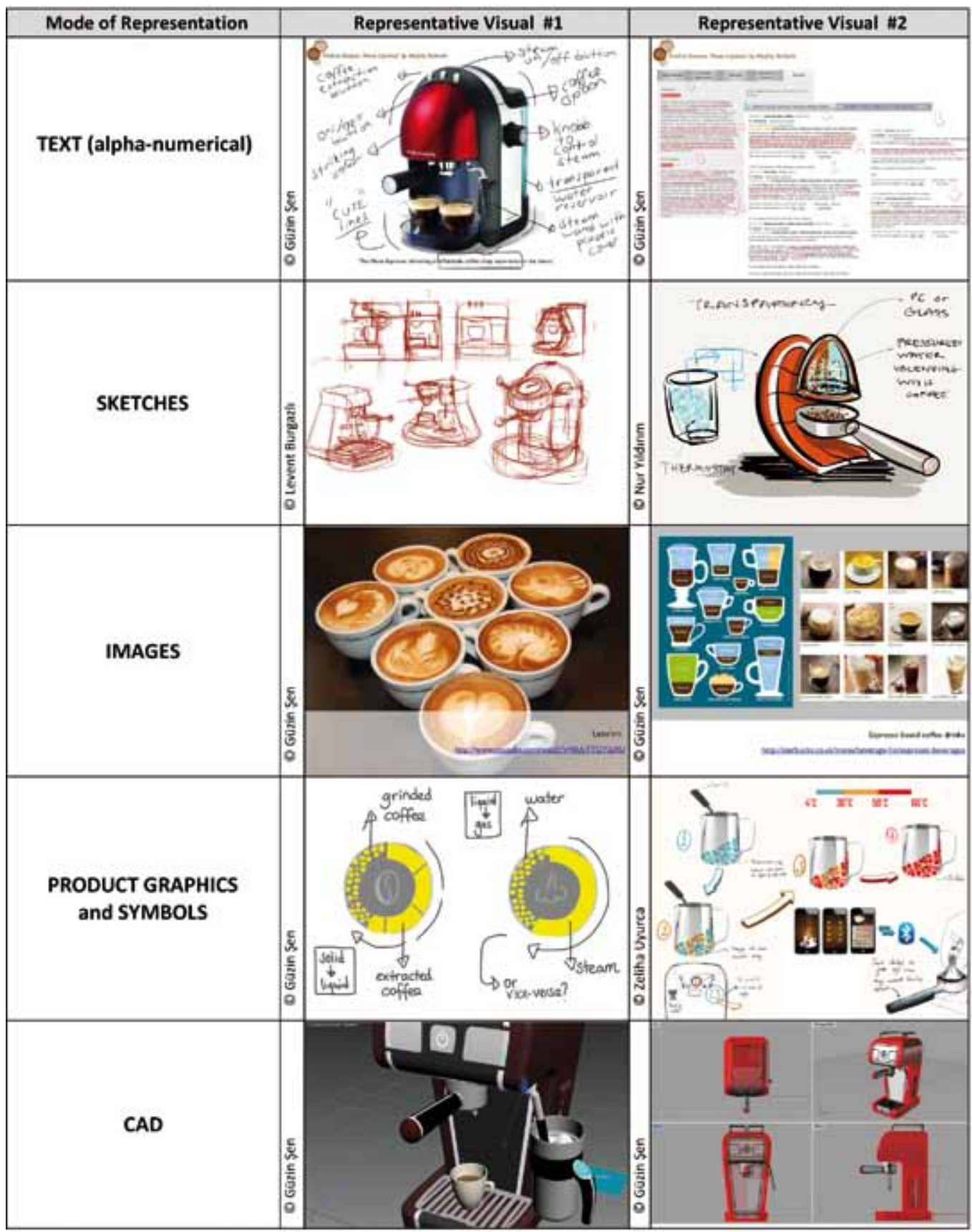


Table 4. Findings from post-project questionnaire with students.

\section{Reasons for Keeping a Paper-Based Sketchbook alongside a Digital}

Sketchbook

- Familiarity for initiating thinking; ease of quickly creating general outlines of product form, 'dirty' drafts, and details; speediness of operating with well-known medium; avoidance of undesirable attention from using new technology; immediate control over pen-paper relationship; spreading out multiple sheets during critiques to help generate new sketches; differing sizes of paper (canvas); pleasant aesthetics of interacting with pen and paper.

\section{Inadequacies Experienced of Paper-Based Sketchbooks}

- Fear of making mistakes with no option for corrections (i.e. having to start over); slowness in manually duplicating visualizations for multiple uses (e.g. for showing interfaces, component assembles); time-consuming to visualize variations of a product; access to limited personal range of visualization tools (e.g. pens, templates); poor manual visualization skills limit professionalism of design communication; not easy to store, carry or organize paperwork (even though content may be digitized); difficult to combine sketches created on different paper sizes.

Advantages Experienced of Digital Sketchbook

- Quick advancement and modification of ideas regarding re-drawing, colouring, textures; possibility of using layers to trace over sketches and photographs, and make modifications; immediacy of sketch manipulation regarding rescaling, rotating, colourizing, copying and arranging; presence of undo / redo lessens anxiety about making mistakes; ability to create clearer and more convincing visualizations; ability to assemble individual drawings onto a larger canvas to create more flowing presentation.

\section{Difficulties Experienced of Digital Sketchbook}

- Time period for adjusting to new technology; technical limitations of location / venue preventing efficient usage; low processor and memory performance of iPad slowed some operations; clear file management strategy needed.

definition, (ii) ideation, and (iii) design finalization. Students were briefed that it was a concept rather than a complete product design project; hence there was no need to attend to the 'inner components' of the product; and there was also no need to deal with manufacturability.

Prior to commencing the project, the digital system was distributed to each of the participant students so that they could familiarize themselves for a week and 'get used' to the new ways of working that it demanded. The students were asked to carry out their entire design process using the digital system, and to upload all of their digitally generated content to a student-specific Dropbox folder on completion of the project. Two examples of uploaded content for each of the modes of representation previously introduced in Table 1 are shown in Table 3.

\section{Questionnaire}

Following completion of the project, students were asked to complete a questionnaire to retrospectively comment on the benefits and drawbacks of generating a digital sketchbook, in comparison to paper-based media. They were also asked to mention good and bad experiences of the chosen digital system. Table 4 contains the findings from the post-project questionnaire.

\section{DISCUSSION AND CONCLUSIONS}

The work presented in this paper sought to examine opportunities and barriers of transitioning from physical to digital student sketchbooks. 
The concept design project used as a test-bed for a digital sketchbook was relatively modest in size (duration of 6 weeks with 4 hours student contact per week) when compared with a full studio course project (typically 15 weeks with 12 hours student contact per week). Therefore, sketchbook content was predictably limited to relatively compressed design activity with reduced scope across design investigations and idea iterations. Nevertheless, as intended, many insights were gained through the feasibility study, concerning digital sketching, digital sketchbooks and digital workflows. The following answers may be given to the research questions Q1-3.

Q1. Regarding 'willingness': Following the interviews during stage 2 of the feasibility study, all students and instructors demonstrated a positive attitude towards adopting a digital sketchbook. There was full willingness to trial the generation of a digital sketchbook to understand its feasibility in an educational setting, within the wider context of adopting increased digital technologies in support of design ideation and development. Participants also expressed some reservations that they expected to occur when switching from physical to digital sketchbooks, mentioned in the answer to Q2.

Q2. Regarding 'expectations': The stage 2 feasibility study interviews revealed the nature of participants' expectations for a digital sketchbook. Considerable enthusiasm was directed towards the ability to quickly manipulate, copy and save digital media, alongside the generation, management and sharing of interactive multimedia content. However, participants' expressed lack of confidence in proficiently using the new medium. They also had doubts that the physical space of a tablet PC would be large enough to work on comfortably in comparison to working at a desk. Concern was also raised about intangibility and lack of connectedness, in the sense that working with a touchscreen tablet presents a 'barrier of glass' to the sketchbook content, which is not present when working directly with a pen on paper.

Q3. Regarding 'implementation': Stage 3 of the feasibility study, focusing on students' experiences of creating a sketchbook and their subsequent reflection through the post-project questionnaire, revealed many comments in relation to the implementation of a digital sketchbook. The main points are as follows.

The students found the experience to draw digitally fun and appreciated the portability and professional visualization offered through the digital system. They thought the system encouraged playfulness and exploration through the provision of multiple tools. In relation to freehand sketching, having an undo/redo feature meant that students did not have to be so cautious, careful or precious about their sketching. Students commented that the graphical tools allowed them to embellish and increase the impact of their freehand sketches, which in turn gave confidence to the designers during the sketching activity.

However, all of the students at some time resorted to paper-based sketching because they were more proficient and familiar with that medium. This echoes previous work: "...despite the increase of computational tools, sketchbooks have qualities that electronic devices cannot mimic. Therefore many designers make use of both" (Wijnen, van den Hoven, 2011). Although the iPad gestural zoom function was praised for working on small details, the zoom function did not satisfactorily 
compensate for the need to work with multiple documents open and spread out on a desk simultaneously. Beyond the experiences mentioned in Table 4, students picked-up on technology-focused experiences of the iPad sketchbook system. Positive experiences were: portability and casual / artistic style of use; good iPad battery life; and diversity of applications. Negative experiences were: the need to use one's wrist rather than arm movement to sketch large radii, owing to the small iPad screen; AluPen nib thickness hinders speedy work and detailing; and lack of pressure sensitivity to create varied line thicknesses results in an interrupted workflow to adjust software line thickness settings.

The iPad apps (and iOS operating system) were not found to be satisfactory as a 'hub' for digital sketchbook content because their file structure is not open to manipulation. Ordering of content across multiple software applications in chronological order was not possible. However, as a portable device for generating photos, videos, and Internet searches - as well as sketches - the iPad was praised. Since the iPad is not compatible with CAD software, its role in design development lessened significantly once students entered the CAD modelling phase of their projects.

If we consider potential follow-up research, refinement of the chosen platform is necessary before making a large-scale implementation of the digital sketchbook in an undergraduate studio project. It would be prudent to offer students a more flexible system, because it is clearly not feasible for students to rely on just one device and work around its limitations. Better use of an organized online repository for design development media can also be beneficial. It can be speculated that a better platform may involve e.g. an iPad as the portable component of a digital sketchbook system, with the main hub for storing and managing project history on a main CAD computer, or via cloud computing. Having a timeframe for managing and presenting sketchbook content is vital. An improved system might have powerful search or filtering options to allow better navigation for instructors, for example sorting through sketchbook content by chronology, mode of representation, design phase, purpose etc. In parallel, improved briefing and training for a digital sketchbook is needed, probably through warm-up projects before students and instructors implement a digital sketchbook for a major project.

\section{BIBLIOGRAPHY}

AL-DOY, N. and EVANS, M. (2011) A review of digital industrial and product design methods in UK higher education, The Design Journal, 14(3), 34368.

AUTODESK (2014) Autodesk SketchBook Pro <Available at: http://www. autodesk.com/products/sketchbook-pro/overview $>$ [Accesses 26.01.2014]

BASKINGER, M. (2008) Pencils before pixels: a primer in hand-generated sketching, ACM Interactions, March/April 2008, 28-36.

BRERETON, R. (2009). Sketchbooks: The hidden art of designers, illustrators $\mathcal{E}$ creative. London: Laurence King.

CHIN, C. and TAN, J. (2007) Use of SketchBook Pro with Tablet PC (TabSketch ${ }^{\mathrm{TM}}$ ) as a design thinking tool in the teaching and learning of design and technology, Proceedings of the Design and Technology Association International Research Conference, 11-20. 
GINSBURG, S. (2011) Are Touchscreen Tablets Effective Design Tools? Smashing Magazine, Available at: <http://www.smashingmagazine. com/2011/03/18/are-touchscreen-tablets-effective-design-toolsreview/> [Accessed 13.03.2013]

HOEBEN, A. and STAPPERS, P. (2001) Ideas: a vision of a designer's sketchingtool, Proceedings of CHI2001, 199-200.

HUMMELS, C. (2000) Gestural Design Tools: Prototypes, experiments and scenarios. Delft: Delft University of Technology Publications.

JONSON, B. (2002) Sketching now, International Journal of Art \& Design Education, 21(3), 246-53.

KAVAKLI, M., SCRIVENER, S. \& BALL, L. (1998) Structure in idea sketching behaviour, Design Studies, 19(4) 485-517.

LEE, B., MALDONADO, H. and KLEMMER, S. (2006) Evaluating augmented idea logs for design education, Stanford Computer Science Technical Report. Available at: <http://hci.stanford.edu/ winograd/cstr/ reports/2006-09.pdf $>$ [Accessed 28.03.2013]

LI, G., CAO, X., PAOLANTONIO, S. \& TIAN, F. (2012) SketchComm: a tool to support rich and flexible asynchronous communication of early design ideas, Proceedings of CSCW-12, 359-68.

NSEAD National Society for Education in Art and Design (2013) Electronic sketchbook and electronic portfolios, Available at: <http://www.nsead. org/ict/about/about14.aspx> [Accessed 28.03.2013]

O'NEILL, S. (2011) RE: Designing a digital sketchbook, Proceedings of C\&C'11: $8^{\text {th }}$ ACM Conference on Creativity and Cognition, 383-4.

OEHLBERGA, L., LAU, K. \& AGOGINO, A. (2009) Tangible interactions in a digital age: medium and graphic visualization in design journals, Artificial Intelligence for Engineering Design, Analysis and Manufacturing, 23(3), 237-249.

OTTOSSON, S. (1998) Qualified product concept design needs a proper combination of pencil-aided design and model-aided design before product data management, Journal of Engineering Design, 9(2) 107-19.

PAO, S-Y., REBEN, A. and LARSON, K. (2012) FlickInk: Bridging the Physical and Digital for Creative Work, Proceedings of SIGGRAPH Asia 2012, Singapore.

PEDGLEY O. (2011) Purposes of drawings in design sketchbooks, Graphicacy and Modelling, eds. E. Norman and N. Seery, Loughborough Design School, Loughborough; 27-50.

REFFAT, R. (2002) Designing with computers in a paperless design computing studio, Proceedings of CAADRIA 2002, 347-54.

SANCHEZ, J. (2010) Ideate: a digital sketchbook, UX Magazine, Article no.511, Available at: <http://uxmag.com/articles/ideate-a-digital-sketchbook> [Accessed 28.03.2013]

SHILLITO, A., SCALI, S. and WRIGHT, M. (2003) Haptics: for a more experiential quality in a computer interface, Proceedings of $5^{\text {th }} \mathrm{EAD}$ Conference. Available at: <http://www.ub.edu/5ead/PDF/9/ ShillitoSW.pdf> [Accessed 09.05.11] 
STAPPERS, P. and SANDERS, E. (2005) Tools for designers, products for users?, Proceedings of the International Conference on Planning and Design, 1-16.

TABARD, A., MACKAY, W. and EASTMOND, E. (2008) From individual to collaborative: the evolution of prism, a hybrid laboratory notebook, Proceedings of ACM Conference on Computer Supported Cooperative Work (CSCW'08), 569-78.

TEMPLE, S. (1994) Thought made visible - the value of sketching, Co-Design Journal, (10.11.12) 16-25.

UNWIN, S. (2009) Notebook architecture, Fieldnotes and Sketchbooks: Challenging the Boundaries between Descriptions and Processes of Describing, ed. W. Gunn, Peter Lang, Berlin.

WANG, J. and KARLSTRÖM, P. (2012) Mobility and multi-modality - an exploratory study of tablet use in interaction design learning, Proceedings of mLearn 2012, 276-79.

WARBURTON, N. (2001) The Impact of Three Dimensional Digital Modelling Media on the Modes of Communication used by Industrial Designers, PhD Thesis, University of Northumbria at Newcastle, UK.

WEAVER, T. (2009) Top draw, New Design, (68) 20-3.

WEIBEL, N., SIGNER, B., NORRIE, M., HOFSTETTER, H., JETTER, H-C. and REITERER, H. (2011) PaperSketch: A Paper-Digital Collaborative Remote Sketching Tool, Proceedings of IUI'11, Palo Alto,155-64.

WIJNEN, J. and VAN DEN HOVEN, E. (2011) Connected sketchbook: linking digital files to physical pages, Proceedings of DESIRE'11, p43-6. Available at: http://dl.acm.org/citation.cfm?id=2079221> [Accessed 28.03.2013]

WORMALD, P. (1997) An enquiry into the present and future role of three dimensional computer modelling as the primary modelling medium for industrial designers, Proceedings of the 2 nd Conference on Computer Aided Architectural Design Research in Asia, 17-19 April, eds. Y. Liu, J. Tsou and J. Hou, National Chioa Tung University, Hsinchu, Taiwan; 257-66.

WU, J., CHEN, C. and CHEN, H. (2012) Comparison of designer's design thinking modes in digital and traditional sketches, Design and Technology Education: An International Journal, 17(3) 37-48.

ZHENG, Z., SUN, L. and SUN, S. (2007) A 3D Sketching Interacting Tool for Physical Simulation Based on Web, Human-Computer Interaction Part II, ed. J. Jacko,Berlin: Springer-Verlag; 710-9.

\section{ACKNOWLEDGEMENTS}

The author would like to thank Res. Asst. Güzin Şen for her help in conducting interviews and reviewing of the student sketchbook contents. Also, thanks are extended to the named students who provided sketchbook images in Table 1 and Table 3. The research carried out was partially resourced by the METU Faculty of Architecture BAP-02-03-2012-001 project. 
Alınd1: 25.06.2013; Son Metin: 30.04.2014

Anahtar Sözcükler: Eskiz defteri; endüstriyel tasarım; tasarım belgelemesi; eğitim; taslak çizim.

\section{SAYISAL ORTAMDA HAZIRLANAN ENDÜSTRIYYEL TASARIM ESKİZ DEFTERLERINNE YÖNELIKK FIZİBILETE ARAŞTIRMASI}

Endüstri ürünleri tasarımcıları ve öğrencileri tasarım fikirlerini oluşturmak, belgelemek, aynı zamanda bu fikirleri başkalarıyla paylaşabilmek için eskiz defteri kullanırlar. Son yıllarda, tasarım süreci giderek sayısal ortamda gerçekleştirilmeye başladı, öyle ki, kağıt-temelli eskiz defterleri tasarım etkinliğini tatmin edici düzeyde belgelemek için yetersiz kalmaya başladı. Bu makale, fiziksel olarak kağıt üstünde oluşturulan endüstriyel tasarım eskiz defterlerinin sayısal olarak hazırlanmasına geçişin eğitim bağlamında fizibiletisinin incelendiği dört aşamalı bir çalışmayı sunmaktadır. Illk olarak, sayısal ortamda hazırlanacak eskiz defteri fikrine prensipte olumlu yaklaşılıp yaklaşılmayacağını ve nedenlerini anlamak üzere endüstriyel tasarım eğitimcileri $(n=5)$ ve öğrencileri $(n=5)$ ile mülakatlar yapıldı.

Ardından, mevcut teknolojilerin kullanımıyla bu fikrin uygulanabilirliğinin sorgulandığ1 ve öğrenci $(n=5)$ tasarım projelerinin aracı olarak kullanıldığ1 bir araştırma gerçekleştirildi. Sayısal tabanlı eskiz defterlerinin denendiği bu araştırmada, Apple iPad, AluPen elektronik kalem, SketchBook Pro, Fiftythree Paper ve Dropbox yazılımları kullanıldı. Fizibilite çalışması kapsamında 60 öğrenciye ait kağıt-temelli eskiz defteri sistematik olarak incelendi. Bu incelemenin amacı, tasarımcıların mevcutta kullandıkları görselleştirme türlerini ve bunlardan hangilerinin dijital eskiz defterinde kullanılabileceğini açığa kavuşturmaktı. Eğitim bağlamından bakıldığında, sayısal eskiz defterinin kabul edilirliğinin ve fizibilitesinin, özellikle öğrencilerin taşınabilirlik ve mesleki görselleştirmeye yönelik verdikleri olumlu tepkilerle pekiştiği gözlendi. Ancak, eskiz defteri içeriğini daha iyi yönetebilmek ve içerikte gezinebilmek için daha gelişmiş sistemlere ihtiyaç olduğu sonucuna varıldı.

BAHAR ŞENER; B.I.D., M.A., Ph.D.

Currently employed as Associate Professor at the Department of Industrial Design, Middle East Technical University, Turkey. Her research and teaching interests centre on opportunities for new and emerging technologies for user-product experience, technologies to improve product design processes, and bespoke product design, customization and 3D printing. bsener@metu.edu.tr 